\title{
An emerging need for developing new models for myocardial infarction as a chronic complex disease: lessons learnt from animal vs. human studies on cardioprotective effects of Erythropoietin in reperfused myocardium
}

\author{
Soroush Seifirad ${ }^{1,2 *}$ \\ ${ }^{1}$ Department of Pediatric Cardiology, Children's Medical Center, Tehran University of Medical Sciences, Tehran, Iran \\ ${ }^{2}$ Endocrinology and Metabolism Research Center, Endocrinology and Metabolism Clinical Sciences Institute, Tehran University of Medical Sciences, Tehran, Iran \\ *Correspondence: sseifirad@gmail.com
}

Edited by:

Gaetano Santulli, Columbia, USA

Reviewed by:

Joel S. Greenberger, University of Pittsburgh Medical Center-Shadyside, USA

Keywords: Erythropoietin, myocardial infarction, animal study, clinical study design, modeling and simulation, complex diseases, chronic disease

\section{INTRODUCTION}

A large number of studies are currently focused on diagnosis, prevention, and treatment of complex disorders. Animal studies are generally utilized as basic models for in-vivo studies and support subsequent clinical trials. Although animal models have so far been fruitful in understanding the mechanism of several diseases and testing the likely prevention and treatment strategies; some of them do not appropriately mimic complex disorders. There is an emerging need for developing new models for chronic complex diseases.

Simplifying a complex system is needed for studying the basis of a complex phenomenon (i.e., Gregor Johann Mendel studies on Pisum sativum to discover genetic inheritance roles); however, these models do not reflect all aspects of a complex system (i.e., epistasis or inter/intraallelic gene suppression). When an animal model is used as the basis of a clinical trial, it is needed to mimic all complex features of the patients.

Myocardial infarction (MI) as a leading cause of mortality and morbidity worldwide has been extensively studied in medicine. MI is an acute phenomenon; however usually it comes after a prolonged period of atherosclerosis which is accompanied by hypoperfusion, hypoxia, and probably degrees of heart failure. As a matter of fact acute $\mathrm{MI}$ is the final sequence of the atherosclerosis as a chronic process.
Animal models of MI generally do not completely mimic MI process. Although atherosclerosis models are currently available (Fuster et al., 2012; Getz and Reardon, 2012), usually MI animal models are surgically mimicked by clumping-reperfusion process (Moon et al., 2003, 2006; Prunier et al., 2007; Doue et al., 2008; Roubille et al., 2013b).

Here, as an example, I have tried to discuss the paradoxical positive results of animal studies on protective effects of Erythropoietin (EPO) administration in reperfused myocardium vs. negative consequences in clinical setting.

It seems that the main fault has been occurred in MI modeling for EPO treatment at the level of animal experimental studies, and followed imprecisely without considering the nature of EPO as a cytokine which is naturally secreted in human, and the pathophysiologic state of $\mathrm{EPO}$ and EPO receptor in atherosclerotic patients. This article will emphasize on the need of developing new models for MI which mimic its complex character rather than criticizing studies on cardioprotective effects of EPO after percutaneous coronary intervention (PCI) in MI.

\section{ERYTHROPOIETIN}

Erythropoietin, traditionally an erythropoiesis stimulator cytokine has been shown to have cell protective properties principally by reducing apoptosis (Van
Der Meer et al., 2005b; Burger et al., 2006, 2009b). EPO may also enhance neovascularization of ischemic tissue (Van Der Meer et al., 2005a; Hirata et al., 2006). Putative cardioprotection of EPO also has been linked to its anti-inflammatory properties (Burger et al., 2009a). It was also reported as one of the protective factors responsible for hypoxemic preconditioning (Cai et al., 2003). EPO cell protective effects on myocardial ischemia were reported in a series of animals as well as human studies; (Cai et al., 2003; Hirata et al., 2005, 2006; Van Der Meer et al., 2005a; Lipsic et al., 2006a,b), however, the results are quit controversial. Some studies hypothesized that Erythropoietin may protect myocardium by direct action on cardiac myocytes and fibroblasts to modify survival and ventricular remodeling (Parsa et al., 2004). The response of coronary artery endothelium to EPO stimulation by NO production was suggested as another probable protective mechanism of EPO on myocardium (Teng et al., 2011).

\section{THE ERYTHROPOIETIN PARADOX: A BRIEF REVIEW ON THE MAIN PUBLISHED TRIALS}

Preliminary animal studies suggest EPO as an efficient mediator for myocardial protection (Van Der Meer et al., 2004b; Burger et al., 2006, 2009b; Westenbrink et al., 2007a; Lipsic et al., 2008; Prunier et al., 2009). For example, Moon et al., showed 
that single systemic administration of EPO dramatically decreased infarct size and contractile dysfunction 8 weeks after induction of MI in rats (Moon et al., 2003).

Following animal experiments, randomized clinical trials (RCT) tried to study myocardial protective properties of EPO. Results of HEBE III study in the Netherlands showed an improvement of left ventricular ejection fraction (LVEF) after administration of EPO in a single dose (Belonje et al., 2008). However, in another RCT conducted in France (EPOMI), Single high-dose EPO after reperfusion in patients with ST elevation MI did not decrease infarct size. They noted that EPO treatment was accompanied by temporary effects on left ventricle size and contractility decreasing the incidence of microvascular obstruction (Prunier et al., 2012). No protective effect was reported in preischemic EPO administration in a published study by Kristensen et al. (2005). According to the results of a published study by Voors et al., a single high dose of EPO after a successful PCI for a ST elevation MI did not improve LVEF after 6 weeks. Nevertheless, the EPO administration was correlated to less major adverse cardiovascular events and an admiring clinical safety profile (Voors et al., 2010). Results of REVEAL study by Najjar et al on 222 patients with ST elevation MI showed no reduction in infarct size and surprisingly were linked with increased rates of adverse cardiovascular events. On the other hand, an increase in infarct size among older patients was also anticipated after subgroup analyses of their patients (Najjar et al., 2011). Roubille et al., in a very recent published study concluded that "Early intracoronary administration of a longer-acting erythropoietin analog in patients with acute MI at the time of reperfusion does not significantly reduce infarct size" (Roubille et al., 2013a).

Finally Meta-Analysis of randomized controlled trials revealed that "Erythropoietin in patients with acute MI seems to have no clinical benefit for heart function or reducing infarct size, cardiovascular events, and all-cause mortality. Erythropoietin may not be a choice for patients with acute MI" (Gao et al., 2012). Paradoxical negative results of human studies vs. positive results of animal studies led to the Erythropoietin paradox in reperfused myocardium protection (Roubille et al., 2013b).

\section{DISCUSSION}

The authors of above mentioned published clinical trials have tried to elucidate their negative findings. However, this tended to repetition of studies with more negative results. They have tried to justify their negative observation as consequence of inclusion criteria (i.e., included patients were not limited to proximal LAD occlusion alone), species differences in EPO response, effective dose, reperfusionEPO infusion therapeutic window (time), and MI sequel evaluation methods (i.e., echocardiography vs. cardiac magnetic resonance imaging, to evaluate infarct size, ejection fraction, and LV function) (Prunier et al., 2007, 2012; Huang et al., 2008; Najjar et al., 2011; Talan et al., 2012; Roubille et al., 2013a,b). A series of above mentioned rationalization have been rejected by later studies (Roubille et al., 2013a).

Atherosclerotic patients usually suffer from degrees of hypoxia, tissue hypoperfussion (i.e., renal hypoperfusion), and anemia which may tend to pathophysiologically high levels of EPO (Gainer, 1987; Shimizu et al., 1988; Van Der Meer et al., 2004a,b, 2008; Westenbrink et al., 2007b). It has been shown that higher levels of EPO are accompanied by higher mortality in a number of patients' subgroups (i.e., Patients with heart failure) (Van Der Meer et al., 2004a). Mortality in these patients mainly originates from cardiovascular accidents. Higher EPO levels reflect poor condition of cardiovascular system and increased likelihood of cardiovascular accidents. Hence, there is a possibility that in case of EPO administration, its role has already been played before MI came to the stage and degrees of EPO resistance is predictable in these patients.

On the other hand, as it has been mentioned above, in the basic animal experiments MI has been produced with no previous hypoxia, no hypoperfusion, no anemia and therefore no high levels of EPO; (Rekhter et al., 1998) hence, It is predictable that externally infused EPO might have protected these animals and had no similarity with the clinical and biochemical state in EPO resistant patients
(Bamgbola et al., 2009; Bamgbola, 2012; Chung et al., 2012; Guerrero-Riscos et al., 2012; Mallick et al., 2012; Okonko et al., 2013). Additonally, renal function, renal perfusion, EPO levels and EPO resistance have not been evaluated in above mentioned clinical trials. Additionally there is likelihood of presence of several unknown mechanisms that changes EPO sensitivity and effectiveness in atherosclerotic patients. We should keep in mind that "Only a good beginning makes a good ending".

\section{CONCLUSION}

In conclusion the Erythropoietin paradox teaches us a very important lesson: let's have a second look at the animal models of MI. When we are studying extrinsic factors, simple MI models are practical to some instance, but when we are studying a naturally secreted factor such as a cytokine, we should note to the chronic background of acute MI and complex character of our patients compared to the simple animal models constructed for a condition such as MI. The Erythropoietin paradox certified inappropriate modeling of MI as a complex phenomenon.

\section{SUGGESTIONS}

New animal models should be developed which mimic chronic complex background of MI. Combination of currently available atherosclerosis models with MI induction techniques could be promising. Recently new state of the art models such as Organ on Chip are introduced; (Huh et al., 2013). Although these new models are at their infancy, they should be considered as future models for in-vivo studies on chronic complex diseases.

\section{ACKNOWLEDGMENTS}

I would like to acknowledge Dr. Vahid Haghpanah, Prof. Alireza Ghafari and Prof. Mahsa M. Amoli for their valuable comments on this article.

\section{REFERENCES}

Bamgbola, O. (2012). Resistance to erythropoietinstimulating agents: etiology, evaluation, and therapeutic considerations. Pediatr. Nephrol. 27, 195-205. doi: 10.1007/s00467-011-1839-4

Bamgbola, O. F., Kaskel, F. J., and Coco, M. (2009). Analyses of age, gender and other risk factors of erythropoietin resistance in pediatric and adult dialysis cohorts. Pediatr. Nephrol. 24, 571-579. doi: 10.1007/s00467-008-0954-3 
Belonje, A. M., Voors, A. A., Van Gilst, W. H., Anker, S. D., Slart, R. H., Tio, R. A., et al. (2008). Effects of erythropoietin after an acute myocardial infarction: rationale and study design of a prospective, randomized, clinical trial (HEBE III). Am. Heart J. 155, 817-822. doi: 10.1016/j.ahj.2007.12.036

Burger, D., Lei, M., Geoghegan-Morphet, N., Lu, X., Xenocostas, A., and Feng, Q. (2006). Erythropoietin protects cardiomyocytes from apoptosis via up-regulation of endothelial nitric oxide synthase. Cardiovasc. Res. 72, 51-59. doi: 10.1016/j.cardiores.2006.06.026

Burger, D., Xenocostas, A., and Feng, Q. P. (2009a). Molecular basis of cardioprotection by erythropoietin. Curr. Mol. Pharmacol. 2, 56-69. doi: 10.2174/1874467210902010056

Burger, D., Xiang, F., Hammoud, L., Lu, X., and Feng, Q. (2009b). Role of heme oxygenase-1 in the cardioprotective effects of erythropoietin during myocardial ischemia and reperfusion. Am. J. Physiol. Heart Circ. Physiol. 296, H84-H93. doi: 10.1152/ajpheart.00372.2008

Cai, Z., Manalo, D. J., Wei, G., Rodriguez, E. R., Fox-Talbot, K., Lu, H., et al. (2003). Hearts from rodents exposed to intermittent hypoxia or erythropoietin are protected against ischemiareperfusion injury. Circulation 108, 79-85. doi: 10.1161/01.CIR.0000078635.89229.8A

Chung, S., Song, H. C., Shin, S. J., Ihm, S. H., Park, C. S., Kim, H. Y., et al. (2012). Relationship between erythropoietin resistance index and left ventricular mass and function and cardiovascular events in patients on chronic hemodialysis. Hemodial. Int. 16, 181-187. doi: 10.1111/j.15424758.2011.00644.x

Doue, T., Ohtsuki, K., Ogawa, K., Ueda, M., Azuma, A., Saji, H., et al. (2008). Cardioprotective effects of erythropoietin in rats subjected to ischemiareperfusion injury: assessment of infarct size with 99mTc-annexin V. J. nucl. Med. 49, 1694-1700. doi: 10.2967/jnumed.107.050260

Fuster, J. J., Castillo, A. I., Zaragoza, C., Ibanez, B., and Andres, V. (2012). Animal models of atherosclerosis. Prog. Mol. Biol. Transl. Sci. 105, 1-23. doi: 10.1016/B978-0-12-394596-9.00001-9

Gainer, J. L. (1987). Hypoxia and atherosclerosis: reevaluation of an old hypothesis. Atherosclerosis 68, 263-266. doi: 10.1016/0021-9150(87)90206-1

Gao, D., Ning, N., Niu, X., Dang, Y., Dong, X., Wei, J., et al. (2012). Erythropoietin treatment in patients with acute myocardial infarction: a metaanalysis of randomized controlled trials. Am. heart j. 164, 715 e711-727 e711. doi: 10.1016/j.ahj.2012. 07.031

Getz, G. S., and Reardon, C. A. (2012). Animal models of atherosclerosis. Arterioscler. Thromb. Vasc. Biol. 32, 1104-1115. doi: 10.1161/ATVBAHA.111.237693

Guerrero-Riscos, M. A., Montes-Delgado, R., SedaGuzman, M., and Praena-Fernandez, J. M. (2012). Erythropoietin resistance and survival in nondialysis patients with stage 4-5 chronic kidney disease and heart disease. Nefrologia 32, 343-352. doi: 10.3265/Nefrologia.pre2012.Jan.11111

Hirata, A., Minamino, T., Asanuma, H., Fujita, M., Wakeno, M., Myoishi, M., et al. (2006). Erythropoietin enhances neovascularization of ischemic myocardium and improves left ventricular dysfunction after myocardial infarction in dogs. J. Am. Coll. Cardiol. 48, 176-184. doi: 10.1016/j.jacc.2006.04.008

Hirata, A., Minamino, T., Asanuma, H., Sanada, S., Fujita, M., Tsukamoto, O., et al. (2005). Erythropoietin just before reperfusion reduces both lethal arrhythmias and infarct size via the phosphatidylinositol-3 kinase-dependent pathway in canine hearts. Cardiovasc. Drugs Ther. 19, 33-40. doi: 10.1007/s10557-005-6895-1

Huang, C. H., Hsu, C. Y., Tsai, M. S., Wang, T. D., Chang, W. T., and Chen, W. J. (2008). Cardioprotective effects of erythropoietin on postresuscitation myocardial dysfunction in appropriate therapeutic windows. Crit. Care Med. 36, S467-S473. doi: 10.1097/CCM.0b013e31818a8cec

Huh, D., Kim, H. J., Fraser, J. P., Shea, D. E., Khan, M., Bahinski, A., et al. (2013). Microfabrication of human organs-on-chips. Nat. Protoc. 8 , 2135-2157. doi: 10.1038/nprot.2013.137

Kristensen, J., Maeng, M., Rehling, M., Berg, J. S., Mortensen,. M., Nielsen, S. S., et al. (2005). Lack of acute cardioprotective effect from preischaemic erythropoietin administration in a porcine coronary occlusion model. Clin. Physiol. Funct. Imaging 25, 305-310. doi: 10.1111/j.1475-097X.2005.00626.x

Lipsic, E., Schoemaker, R. G., Van Der Meer, P., Voors, A. A., Van Veldhuisen, D. J., and Van Gilst, W. H. (2006a). Protective effects of erythropoietin in cardiac ischemia: from bench to bedside. J. Am. Coll. Cardiol. 48, 2161-2167. doi: 10.1016/j.jacc.2006.08.031

Lipsic, E., Van Der Meer, P., Voors, A. A., Westenbrink, B. D., Van Den Heuvel, A. F., De Boer, H. C., et al. (2006b). A single bolus of a long-acting erythropoietin analogue darbepoetin alfa in patients with acute myocardial infarction: a randomized feasibility and safety study. Cardiovasc. Drugs Ther. 20, 135-141. doi: 10.1007/s10557-006-7680-5

Lipsic, E., Westenbrink, B. D., Van Der Meer, P., Van Der Harst, P., Voors, A. A., Van Veldhuisen, D. J., et al. (2008). Low-dose erythropoietin improves cardiac function in experimental heart failure without increasing haematocrit. Eur. J. Heart Fail. 10, 22-29. doi: 10.1016/j.ejheart.2007.10.008

Mallick, S., Rafiroiu, A., Kanthety, R., Iqbal, S., Malik, R., and Rahman, M. (2012). Factors predicting erythropoietin resistance among maintenance hemodialysis patients. Blood Purif. 33, 238-244. doi: 10.1159/000335256

Moon, C., Krawczyk, M., Ahn, D., Ahmet, I., Paik, D., Lakatta, E. G., et al. (2003). Erythropoietin reduces myocardial infarction and left ventricular functional decline after coronary artery ligation in rats. Proc. Natl. Acad. Sci. U.S.A. 100, 11612-11617. doi: 10.1073/pnas.1930406100

Moon, C., Krawczyk, M., Lakatta, E. G., and Talan, M. I. (2006). Therapeutic effectiveness of a single vs multiple doses of erythropoietin after experimental myocardial infarction in rats. Cardiovasc. Drugs Ther. 20, 245-251. doi: 10.1007/s10557006-0080-z

Najjar, S. S., Rao, S. V., Melloni, C., Raman, S. V., Povsic, T. J., Melton, L., et al. (2011). Intravenous erythropoietin in patients with ST-segment elevation myocardial infarction: REVEAL: a randomized controlled trial. JAMA 305, 1863-1872. doi: 10.1001/jama.2011.592
Okonko, D. O., Marley, S. B., Anker, S. D., PooleWilson, P. A., and Gordon, M. Y. (2013). Erythropoietin resistance contributes to anaemia in chronic heart failure and relates to aberrant JAK-STAT signal transduction. Int. J. Cardiol. 164, 359-364. doi: 10.1016/j.ijcard.2011.07.045

Parsa, C. J., Kim, J., Riel, R. U., Pascal, L. S. Thompson, R. B., Petrofski, J. A., et al. (2004). Cardioprotective effects of erythropoietin in the reperfused ischemic heart: a potential role for cardiac fibroblasts. J. Biol. Chem. 279, 20655-20662. doi: 10.1074/jbc.M314099200

Prunier, F., Biere, L., Gilard, M., Boschat, J., Mouquet, F., Bauchart, J. J., et al. (2012). Single high-dose erythropoietin administration immediately after reperfusion in patients with ST-segment elevation myocardial infarction: results of the erythropoietin in myocardial infarction trial. Am. Heart $j$. 163, 200 e201-207 e201. doi: 10.1016/j.ahj.2011. 11.005

Prunier, F., Pfister, O., Hadri, L., Liang, L., Del Monte, F., Liao, R., et al. (2007). Delayed erythropoietin therapy reduces post-MI cardiac remodeling only at a dose that mobilizes endothelial progenitor cells. Am. J. Physiol. Heart Circ. Physiol. 292, H522-H529. doi: 10.1152/ajpheart. 00357.2006

Prunier, F., Pottier, P., Clairand, R., Mercier, A., Hajjar, R. J., Planchon, B., et al. (2009). Chronic erythropoietin treatment decreases post-infarct myocardial damage in rats without venous thrombogenic effect. Cardiology 112, 129-134. doi: $10.1159 / 000142723$

Rekhter, M. D., Hicks, G. W., Brammer, D. W. Work, C. W., Kim, J. S., Gordon, D., et al. (1998). Animal model that mimics atherosclerotic plaque rupture. Circ. Res. 83, 705-713. doi: 10.1161/01.RES.83.7.705

Roubille, F., Micheau, A., Combes, S., Thibaut, S., Souteyrand, G., Cayla, G., et al. (2013a). Intracoronary administration of darbepoetinalpha at onset of reperfusion in acute myocardial infarction: results of the randomized Intra-CoEpoMI trial. Arch. Cardiovasc. Dis. 106, 135-145. doi: 10.1016/j.acvd.2012.12.001

Roubille, F., Prunier, F., Barrere-Lemaire, S., Leclercq, F., Piot, C., Kritikou, E. A., et al. (2013b). What is the role of erythropoietin in acute myocardial infarct? Bridging the gap between experimental models and clinical trials. Cardiovasc. Drugs Ther. 27, 315-331. doi: 10.1007/s10557-0136461-1

Shimizu, S., Nara, Y., Yamada, K., Keiser, H. R. and Yamori, Y. (1988). Cellular mechanisms of hypertension and atherosclerosis: hypoxiainduced lipid accumulation in cultured vascular smooth muscle cells from the stroke-prone spontaneously hypertensive rat. J. hypertens. Suppl. 6, S163-S165.

Talan, M. I., Ahmet, I., and Lakatta, E. G. (2012) Did clinical trials in which erythropoietin failed to reduce acute myocardial infarct size miss a narrow therapeutic window? PLoS ONE 7:e34819. doi: 10.1371/journal.pone.0034819

Teng, R., Calvert, J. W., Sibmooh, N., Piknova, B., Suzuki, N., Sun, J., et al. (2011). Acute erythropoietin cardioprotection is mediated by endothelial response. Basic Res. Cardiol. 106, 343-354. doi: 10.1007/s00395-011-0158-z 
Van Der Meer, P., Lipsic, E., Henning, R. H., Boddeus, K., Van Der Velden, J., Voors, A. A., et al. (2005a). Erythropoietin induces neovascularization and improves cardiac function in rats with heart failure after myocardial infarction. J. Am. Coll. Cardiol. 46, 125-133. doi: 10.1016/j.jacc.2005.03.044

Van Der Meer, P., Lipsic, E., Van Gilst, W. H., and Van Veldhuisen, D. J. (2005b). Erythropoietin: from hematopoiesis to cardioprotection. Cardiovasc. Drugs Ther. 19, 7-8. doi: 10.1007/s10557-0056891-5

Van Der Meer, P., Lok, D. J., Januzzi, J. L., De La Porte, P. W., Lipsic, E., Van Wijngaarden, J., et al. (2008). Adequacy of endogenous erythropoietin levels and mortality in anaemic heart failure patients. Eur. Heart J. 29, 1510-1515. doi: 10.1093/eurheartj/ehn205

Van Der Meer, P., Voors, A. A., Lipsic, E., Smilde, T. D., Van Gilst, W. H., and Van Veldhuisen, D. J. (2004a). Prognostic value of plasma erythropoietin on mortality in patients with chronic heart failure. J. Am. Coll. Cardiol. 44, 63-67. doi: 10.1016/j.jacc.2004.03.052
Van Der Meer, P., Voors, A. A., Lipsic, E., Van Gilst, W. H., and Van Veldhuisen, D. J. (2004b). Erythropoietin in cardiovascular diseases. Eur. Heart J. 25, 285-291. doi: 10.1016/j.ehj.2003.11.017

Voors, A. A., Belonje, A. M., Zijlstra, F., Hillege, H. L., Anker, S. D., Slart, R. H., et al. (2010). A single dose of erythropoietin in ST-elevation myocardial infarction. Eur. Heart J. 31, 2593-2600. doi: 10.1093/eurheartj/ehq304

Westenbrink, B. D., Lipsic, E., Van Der Meer, P. Van Der Harst, P., Oeseburg, H., Du Marchie Sarvaas, G. J., et al. (2007a). Erythropoietin improves cardiac function through endothelial progenitor cell and vascular endothelial growth factor mediated neovascularization. Eur. Heart J. 28, 2018-2027. doi: 10.1093/eurheartj/ ehm 177

Westenbrink, B. D., Visser, F. W., Voors, A. A., Smilde, T. D., Lipsic, E., Navis, G., et al. (2007b). Anaemia in chronic heart failure is not only related to impaired renal perfusion and blunted erythropoietin production, but to fluid retention as well. Eur. Heart J. 28, 166-171. doi: 10.1093/eurheartj/ehl419

Received: 08 December 2013; accepted: 23 January 2014; published online: 11 February 2014.

Citation: Seifirad S (2014) An emerging need for developing new models for myocardial infarction as a chronic complex disease: lessons learnt from animal vs. human studies on cardioprotective effects of Erythropoietin in reperfused myocardium. Front. Physiol. 5:44. doi: 10.3389/fphys.2014.00044

This article was submitted to Clinical and Translational Physiology, a section of the journal Frontiers in Physiology.

Copyright (C) 2014 Seifirad. This is an open-access article distributed under the terms of the Creative Commons Attribution License (CC BY). The use, distribution or reproduction in other forums is permitted, provided the original author(s) or licensor are credited and that the original publication in this journal is cited, in accordance with accepted academic practice. No use, distribution or reproduction is permitted which does not comply with these terms. 